\title{
Kurumsal Kalite ve Gelir: Panel Veri Analizi*
}

\author{
Sedat ALATAŞ, Osman PEKER ${ }^{* *}$
}

\begin{abstract}
Kurumsal Kalite ve Gelir: Panel Veri Analizi
Özet

Bu çalışmada, kurumsal kalite ile gelir arasındaki ilişki, 1996-2012 dönemi temel alınarak, 122 ülke için Panel EKK yöntemi ile analiz edilmiştir. Ampirik analizlerden elde edilen üç önemli sonuç bulunmaktadır. Birinci olarak, kurumsal kalite ile gelir arasında pozitif ve istatistiki olarak anlamlı ilişki bulunmaktadır. İkinci olarak, kurumsal kalitenin gelir üzerindeki etkisi ülke gruplarına göre farkılış̧maktadır. En yüksek olduğu ülkeler, Avrupa ile Sahra Altı ülkeleri iken; en düşük olduğu ülkeler, Doğu ve Güney Doğu Asya ülkeleri ile Kuzey ve Latin Amerika ülkeleridir. Üçüncüsü ise, kurumsal kalitenin gelire etkisi, ekonomik kalkınmaya yeni başlayacak/başlamış olan ülkelerde ve ekonomik kalkınmasını büyük ölçüde tamamlamış ülkelerde daha yüksektir. Bu nedenle, özellikle azgelişmişülkelerin, kurumsal kalitelerini iyileştirmeye yönelikgerekli hukuksal düzenlemeleri yaparak, rüşvet ve yolsuzluğu azaltmalı, mülkiyet haklarını güvence altına alan, işgücü ve iş özgürlüğüne önem veren iyi kurumları oluşturmaları gerekmektedir.
\end{abstract}

Institutional Quality and Income: Panel Data Analysis

Abstract

In this study, the impact of institutional quality on income is examined by panel OLS by using 1996-2012 period data for 122 countries. The empirical findings yield three striking results. Firstly, there is a positive and statistically significant relationship between institutional quality and income. Secondly, it is found that the impact of institutional quality on income differs among groups of countries. While the effect of institutional quality on income is high in magnitude in European and Sub-Saharan countries, it is low in Latin and North America and East and South East Asia countries. Thirdly, in those countries which have substantially completed and have newly started its economic development, the impact of institutional quality on income is higher. Hence, less developed countries should focus on legal arrangements and business freedom in order to reduce corruption and secure property rights.

Key Words: Income, Institutional Quality, Panel Data

\section{Giriş}

Genel olarak, uzun dönemde ekonomik büyümenin yanında, ekonomik yapının ve çıktı dağılımının değiştirilmesini öngören ekonomik kalkınma, yoksul kesimi oluşturan bireylerin maddi refahının iyileştirilmesinden, tarım sektörünün üretimdeki payının azaltılıp, sanayi ve hizmetler sektörünün paylarının artırılmasına, eğitim sisteminde kalitenin yükseltilmesinden, nitelikli işgücünün yetiştirilmesine kadar çok çok sayıda dönüşümü kapsamaktadır (Nafziger, 2006: s. 15). Söz konusu dönüşümün farklı düzeylerde gerçekleşmesi, yoksul ve zengin ülkeler arasındaki gelir farkının daha da büyümesine neden olmaktadır. Dünya Bankası (2013) verilerine göre, yüksek gelirli ülkelerin kiş̧i başı ortalama gelirinin düşük gelirli ülkelerin kişi başı ortalama gelirinden yaklaşık 65 kat daha fazla olması bunun en açık göstergesidir.

\footnotetext{
*Bu çalışma, Adnan Menderes Üniversitesi Sosyal Bilimler Enstitüsü’nde hazırlanan “ Ekonomik Kalkınmayı Belirleyen Faktörler: Ampirik Analiz" adlı yüksek lisans tezinden üretilmiştir.

** Sedat ALATAŞ, Arş.Gör., Adnan Menderes Üniversitesi, iktisat Bölümü, sedat.alatas@adu.edu.tr; Osman PEKER, Doç.Dr., Adnan Menderes Üniversitesi, iktisat Bölümü, ottopeker@gmail.com
} 


\section{Sedat ALATAŞ | Osman PEKER}

Yoksul ve zengin ülkeler arasındaki gelir farlılıklarının nedenleri birçok araştırmacı tarafından önceleri işgücü, sermaye birikimi, eğitim, sağlık ve benzeri faktörlere dayandırımış iken; modern kalkınma literatüründe yerini ülkenin coğrafyası, dışa açıkığı ve kurumsal kalitesi gibi belirleyicilere bırakmıştır (Rodrik vd., 2002; Bloch ve Tang, 2004: s. 245; Meier ve Stiglitz, 2000; Acemoğlu, 2003: s. 27; Hall ve Jones, 1998: s. 1; Acemoğlu vd., 2004: s. 1).

Ülkelerarası zenginlik farkılıklarının en önemli nedeninin coğrafi yapıyla ilişkili olan faktörler olduğunu öne süren araştırmacılar, iklim, doğal kaynaklar, ulaşım maliyetleri, hastalıklar ve benzerlerinin ülkelerin geleceğini belirlediğini, dolayısıyla kişi başına gelirdeki farklııkların temelinde coğrafi yapının olduğunu ileri sürmüşlerdir. İkinci önemli faktör, uluslararası ticaretin verimlilik etkisine odaklanan dışa açıklıktır. Buna göre, dışa açıklık, kişi başına geliri hem doğrudan (mutlak ve karşılaştırmalı avantaj sağlayarak) hem de dolaylı olarak (teknoloji aktarımı sağlayarak ve ölçek ekonomilerini arttırarak) etkilemekte, dolayısıyla dışa açık ekonomiler, dışa kapalı ekonomilere göre daha hızlı sermaye birikimi sağlayıp, gelişmektedir (Bloch ve Tang, 2004: s. 248; Rodrik vd., 2002).

Son faktörü savunan görüşte ise, coğrafyanın ve dışa açıklığın kişi başı gelir farklılıklarının sadece bir kısmını açıkladığını, asıl belirleyici olanın ülkenin kurumsal kalitesi olduğu dile getirilmiştir. Kurumsal kalitedeki iyileşmeler, mülkiyet haklarını ve bireylerarası sözleşmeleri güvence altına almak suretiyle yolsuzluk ve rüşveti azaltmakta; bu ise, geliri pozitif yönde etkilemektedir. Çünkü kurumsal yapının gelişmiş olduğu ülkelerde, bireyler, ekonomik ve toplumsal yaşamda aktif olarak yer almakla birlikte, elit kesim ve siyasetçilerin davranışları sınırlandırılır. Toplumda adalet ortamının oluşmasını sağlayan bu süreçte, gelirin sadece büyüklüğü değil bölüşümü de belirlenir (North, 1990: 110; North ve Wallis, 1994: 609; Yapraklı, 2008; Dampare ve Piesse, 2002: s. 2; Aron, 2000: s. 104; Acemoğlu ve Johnson, 2003: s. 1).

Bu kapsamda, çalışmada kurumsal kalitenin gelir üzerindeki etkisi 122 ülke için araştırılmıştır. 1996-2012 yıllarını kapsayan dönemde yöntem olarak panel veri analizi kullanıımıştır. Çalışmanın literatüre iki açıdan katkı yapacağı düşünülmektedir: (i) kurumsal kalite ve gelir ilişkisine yeni bir ampirik kanıt sağlanmıştı; (ii) kurumsal kalite ile gelir arasındaki ilişki alt ülke sepetleri için ayrı ayrı analiz edilmiştir. Böylelikle, heterojenlikten kaynaklanan belirsiz ortadan kaldırımış, bu doğrultuda daha doğru ve etkin politika önerileri geliştirilmiştir. Çalışmanın bundan sonraki kısmı dört bölümden oluşmaktadır. İkinci bölümde, teorik ve ampirik literatür; üçüncü bölümde, veri analizi, model ve yöntem; dördüncü bölümde uygulama ve bulgular; son bölümde ise, sonuç ve genel bir değerlendirmeye yer verilmiştir.

\section{Teorik ve Ampirik Literatür}

Kurumsal kalitenin gelire etkisi, ilgili literatürün en önemli tartışma alanlarından birini oluşturur. Burada, esas olarak, mülkiyet hakları, hukukun üstünlüğü ve devletin rolü gibi faktörler incelenmiş ve iyi kurumlara sahip toplumların, beşeri sermayeye, sanayileşmeye ve teknolojiye daha fazla kaynak aktarmak suretiyle ekonomik zenginliği daha hızlı gerçekleştireceği görüşü ileri sürülmüştür. 
Bireylerin, devlete ve elit kesime karşı mülkiyet haklarını güvence altına alan kurumlar, kuşkusuz ekonomik büyümeyi de teşvik edecektir. Kurumsal yapısını bu yönde geliştiren ülkeler, mülkiyet hakları ve sözleşme kurumlarını etkin bir şekilde kullanabilmesi nedeniyle, daha yüksek kişi başına gelire, yatırım oranına ve daha gelişmiş bir borsa yapısına sahip olur (Acemoğlu ve Johnson, 2003). Dolayısıyla, ülkelerin kurumsal yapılarındaki farklılıklar kaynak dağılımı ve ekonomik performansı belirleyeceği için (Acemoğlu vd., 2004), neden bazı ülkelerin daha gelişmiş, bazılarının ise daha azgelişmiş olduğunun yanıtı da ortaya çıkar.

Kurumsal kalitedeki artışın bir diğer etkisi kayıt dışı ekonominin toplam ekonomi içindeki payının düşmesine ve şeffaflığın artışına ilişkindir. Yolsuzluk ve rüşvetçiliğin azalışına yol açan bu süreç (Aron, 2000: s. 104), bir taraftan ekonomik ve politik istikrarı sağlayacak; öte yandan kaynakların verimsiz alanlardan üretken ve istihdam sağlayan verimli alanlara yönelmesine neden olacaktır (Yapraklı, 2008: s. 303; Dampare ve Piesse, 2002: s. 2).

Gelir, ekonomik büyüme ya da kalkınma ile kurumsal kalite arasındaki ilişkinin yönünün pozitif olduğu sunulan ampirik literatürden anlaşılmaktadır. North ve Thomas (1970), mülkiyet haklarındaki gelişmeler, verimlilik ve ekonomik performans arasında pozitif ilişkiyi tespit etmiştir. Knack ve Keefer' de (1995), mülkiyet haklarının korunmasının hem yatırımlarda hem de girdi dağılımında etkinliği sağladığını, dolayısıyla ekonomik büyüme ve yatıımlar üzerinde büyük etkisinin olduğunu belirlemiştir.

Scully (1988), 1960-1980 dönemi verileriyle, 115 ülkeyi incelediği çalışmasında, siyasi olarak açık, hukukun ve mülkiyet haklarının üstünlüğüne inanan ülkelerin büyüme oranlarının diğer ülkelere göre daha yüksek olduğunu tespit etmiştir. Benzer şekilde, Spindler (1991) ekonomik özgürlük ile ekonomik kalkınma arasında güçlü ve doğrudan bir ilişki olduğu bulgusunu elde etmiştir. Alesina ve Perotti (1993), 1960-1985 dönemini temel alarak 70 ülke için yaptığı çalışmada, gelir eşitsizliğinin, sosyal-politik istikrarsızlık kanalıyla siyasi ve ekonomik belirsizliğe neden olduğunu ve yatırımları azalttığını ortaya koymuştur. Mauro (1995), 1960-1985 dönemi verilerini kullanarak yolsuzluk, ekonomik büyüme ve yatırımlar arasında istatistiksel olarak anlamlı ters yönlü bir ilişkiye rastlamıştır. Dawson (1998), 1975-1990 yılları arası verileri kullanarak 85 ülke için elde ettiği bulgulara göre, serbest piyasa kurumları büyümeyi pozitif yönde uyarmaktadır. Ekonomik özgürlük, ekonomik büyümeyi toplam faktör verimliliği kanalıyla doğrudan, yatırım kanalıyla dolaylı olarak etkilemekte; siyasi ve sivil özgürlük yatırımları teşvik etmektedir.

Hall ve Jones' un (1999), neden bazı ülkelerin diğer ülkelerden daha fazla üretken oldukları sorusunun cevabını aradığı çalışmasında, ülkelerarası kişi başına çıktıdaki farklılığın sadece bir kısmının fiziki sermaye ve eğitim başarısıyla açıklanabileceği, asıl önemli olanın sosyal altyapı olarak adlandırılan kurumsal farklılıklar ve hükümet politikaları olduğunu ileri sürmüştür. 127 ülke için yapılan bu çalışmada kişi başına çıktı ile sosyal altyapı arasında güçlü ve yakın bir ilişki bulunmuştur. Vijayaraghavan ve Ward (2001), 45 ülke için 1975-1990 dönemi veriyle yaptığı çalışmada, mülkiyet haklarının korunması ile ekonomik büyüme oranları arasında önemli bir ilişki bulmuştur. 
Panel Veri Analizi ve Kümeleme Analizi kullanılarak yapılan başka bir çalışmada ise, Gökalp ve Baldemir (2006), ifade özgürlügü ve şeffaflığın, politik istikrar ve şiddet yokluğunun, yönetim etkinliğinin, düzenlemelerin kalitesinin, hukukun üstünlüğünün, yolsuzluğun önlenmesinin ekonomik büyüme üzerindeki etkisini incelemiştir. Elde edilen bulgulara göre, ifade özgürlüğü ve şeffaflık, politik istikrar, düzenlemelerin kalitesi ve hukukun üstünlüğü ile ekonomik büyüme arasında negatif, yönetimin etkinliği ve yolsuzluğun önlenmesi ile ekonomik büyüme arasında pozitif yönlü ilişki bulunmuştur.

Türkiye' nin de içinde bulunduğu 36 üst orta gelir düzeyindeki ülke için yapılan başka bir panel veri analizinde, Yapraklı (2008), ifade özgürlüğü ve şeffaflık, politik istikrar, düzenlemelerin kalitesi ve hukukun üstünlüğü değişkenleri ile ekonomik büyüme arasında negatif, yönetimin etkinliği ve yolsuzluğun önlenmesi ile ekonomik büyüme arasında pozitif yönlü ilişki bulmuştur.

Yoo ve Steckel (2010), Japonya ve onun kolonileri olan Kore, Tayvan ve Palau ülkeleri için mülkiyet hakları ile ekonomik kalkınma arasındaki ilişkiyi analiz etmiştir. Elde edilen sonuçlar iyi tanımlanmış mülkiyet haklarının ekonomik kalkınmanın gerçekleştirilmesinde önemli bir rolünün olduğunu göstermiştir. Benzer şekilde, Mitchener ve Ohnuki (2008) teknolojik ve kurumsal yeniliklerin Japonya' nın ulusal sermaye piyasasını belirlemede önemli rolünün olduğunu belirlemiştir. Luo ve Wen (2015) kurumsal kalitenin gelire etkisinin sanayileşmiş ülkelerde geçerli olduğunu, söz konusu ilişkinin kırsal ekonomiler için geçerli olmadığını ortaya koymuştur.

\section{Veri Analizi, Model ve Yöntem}

Bu çalışmada, kurumsal kalite ile gelir arasındaki ilişki, 1996-2012 dönemi temel alınarak, panel veri yöntemi ile 122 ülke için tahmin edilmiştir. Söz konusu ülkeler ve dönem, verilerin ulaşılabilirliğine göre belirlenmiştir. Toplam iki değişkenli yapılan çalışmada, geliri temsilen kişi başına GSYH (sabit fiyatlarıyla Amerikan \$) (INC) ve kurumsal kaliteyi temsilen ekonomik özgürlük endeksi (OVE) kullanılmıştır. Kişi başına GSYH, Dünya Bankası Kalkınma Göstergeleri (World Bank Development Indicators) veri tabanından, ekonomik özgürlük endeksi ise Miras Vakfından (Heritage Foundation) derlenmiştir ${ }^{1}$. Ekonomik özgürlük endeksi, özel olarak belirlenmiş 10 bileşenin ortalaması alınarak hesaplanmış ve dört başlık altında toplanmıştır: 1. Hukukun üstünlüğü: mülkiyet hakları ve yolsuzluk; 2. Devletin rolü: mali özgürlük ve hükümet harcamaları; 3 . Mevzuatın etkinliği: iş özgürlüğü, işgücü özgürlüğü ve parasal özgürlük; 4. Serbest piyasa: ticaret özgürlüğü, yatırım özgürlügü ve finansal özgürlük. Söz konusu edilen 10 bileşen 0 ile 100 arasında değer almaktadır.

Ele alınan 122 ülke belirlenirken Dünya Bankası' nın ülkelerin bulunduğu bölgeyi baz alarak yapmış olduğu sınıflandırma temel alınmıştır. Buna göre, Doğu ve Güney Asya, Avrupa, Orta Doğu ve Kuzey Afrika, Kuzey ve Latin Amerika, Sahra Altı Afrika olmak üzere beş kategoriye ayrılmıştır. Buna

\footnotetext{
${ }^{1}$ Daha detaylı bilgi için bk. -Heritage Foundation- http://www.heritage.org/index/explore-
} 
göre, kurumsal kalitenin gelir üzerindeki etkisi her bir kategori için 5 farklı logaritmik model oluşturularak araştırılmıştır².

Model 1: Doğu ve Güney Asya ülkeleri için:

$$
\operatorname{lnINC} 1_{\mathrm{it}}=\beta_{1 \mathrm{i}}+\beta_{2 \mathrm{i}} \operatorname{lnOVE} 1_{\mathrm{it}}+\mathrm{u}_{\mathrm{it}}
$$

Model 2: Avrupa ülkeleri için:

$$
\operatorname{lnINC} 2_{\mathrm{it}}=\beta_{3 \mathrm{i}}+\beta_{4 \mathrm{i}} \operatorname{lnOVE} 2_{\mathrm{it}}+\mathrm{u}_{\mathrm{it}}
$$

Model 3: Orta Doğu ve Kuzey Afrika ülkeleri için:

$$
\operatorname{lnINC}_{\mathrm{it}}=\beta_{5 \mathrm{i}}+\beta_{6 \mathrm{i}} \ln \mathrm{OVE} 3_{\mathrm{it}}+\mathrm{u}_{\mathrm{it}}
$$

Model 4: Kuzey ve Latin Amerika ülkeleri için:

$$
\operatorname{lnINC4}_{\text {it }}=\beta_{7 \mathrm{i}}+\beta_{8 \mathrm{i}} \operatorname{lnOVE}_{\mathrm{it}}+\mathrm{u}_{\mathrm{it}}
$$

Model 5: Sahra Altı Afrika ülkeleri için:

$$
\operatorname{lnINC5} 5_{i t}=\beta_{9 i}+\beta_{10 \mathrm{i}} \operatorname{lnOVE} 5_{i t}+\mathrm{u}_{\mathrm{it}}
$$

Panel veri analizi kapsamında, öncelikle paneli oluşturan yatay kesitler (ülkeler) arasındaki bağımlılık testi yapılmıştır. Daha sonra, serilerin düzey değerinde durağan olup olmadıkları analiz edilmiş, bu amaçla yatay kesit bağımlıı̆̆ını göz önünde bulunduran ve bulundurmayan panel birim kök testlerine yer verilmiştir. Son olarak, sabit etkiler ve rassal etkiler modeli varsayımı altında, model tahminleri yapılmıştır.

\section{Uygulama ve Bulgular}

\subsection{Yatay Kesit Bağımlılığının Tespit Edilmesi}

Panel veri analizinde dikkat edilmesi gereken en önemli hususlardan biri ülkeler arasında yatay kesit bağımlılı̆ının var olup olmadığıdır. Ülkeler arasında yatay kesit bağımlılı̆ının dikkate alınmasının nedeni, yüksek derecede küreselleşme, uluslararası ticaret ve finansal bütünleşme sonucu, ülkelerin birinde meydana gelen bir şokun diğer ülkeleri de etkileyebilmesi ve yatay kesit bağımlılı̆ının inmal edildiği durumlarda, panel veri analizinde bazı çarpıklıkların ve bozulmaların meydana gelmesidir (Pesaran, 2006: 3). Bu nedenle, panel veri analizine ülkeler arasında yatay kesit bağımlılığının varlığının test edilmesiyle başlanmıştır. Bu amaçla, Breusch ve Pagan (1980) tarafından önerilen Lagrange Çarpanı (LM) test istatistiği kullanılmıştır (Pesaran, 2004: s. 4):

\footnotetext{
${ }^{2}$ Her model için kullanılan değişkenler aynıdır: sabit fiyatlar ile kişi başına GSYH (INC) ve ekonomik özgürlük endeksi (OVE).
} 


$$
\mathrm{CD}_{\mathrm{LM} 1}=\mathrm{T} \sum_{\mathrm{i}=1}^{\mathrm{N}-1} \sum_{\mathrm{j}=\mathrm{i}+1}^{\mathrm{N}} \hat{\rho}_{\mathrm{ij}}^{2} \sim \chi_{\mathrm{N}(\mathrm{N}-1) / 2}^{2}
$$

$\hat{\rho}_{i j}$, bireysel En Küçük Kareler Yöntemi tahminlerinden elde edilen tahmini artık terimler arasındaki ilişkiyi gösteren katsayıları ifade etmektedir. Söz konusu test istatistiği $T \rightarrow \infty$ ve $N \rightarrow$ fixed, yani T sonsuza giderken ve $\mathrm{N}$ sabitken kullanilır.

Denklem (6)'da tanımlanan test $N \rightarrow \infty$ iken kullanılamamaktadır. Bu durumda $T \rightarrow \infty$ ve $N \rightarrow \infty$ iken, Denklem (7)'de tanımlanan LM test istatistiği kullanılmaktadır (Pesaran, 2004: s. 5):

$$
\mathrm{CD}_{\mathrm{LM} 2}=\sqrt{\frac{1}{\mathrm{~N}(\mathrm{~N}-1)}} \sum_{\mathrm{i}=1}^{\mathrm{N}-1} \sum_{\mathrm{j}=\mathrm{i}+1}^{\mathrm{N}} \mathrm{T}\left(\hat{\rho}_{\mathrm{ij}}^{2}-1\right) \sim \mathrm{N}(0,1)
$$

Denklem (7)'de, N' nin T'y yöre oldukça büyük olduğu durumlarda çarpıklık ortaya çıkabilmektedir. Bu nedenle, Denklem (8)'de tanımlanan $C D_{L M 3}$ testi geliştirilmiştir (Pesaran, 2004: s. 5):

$$
\mathrm{CD}_{\mathrm{LM} 3}=\sqrt{\frac{2 \mathrm{~T}}{\mathrm{~N}(\mathrm{~N}-1)}}\left(\sum_{\mathrm{i}=1}^{\mathrm{N}-1} \sum_{\mathrm{j}=\mathrm{i}+1}^{\mathrm{N}} \hat{\rho}_{\mathrm{ij}}^{2}\right) \sim \mathrm{N}(0,1)
$$

Bunların dışında, Breusch-Pagan LM testinde ortaya çıkan sapmayı test istatistiğine varyansı ve ortalamayı ekleyerek düzelten bir test daha tanımlanmıştır (Pesaran vd., 2008):

$$
\mathrm{CD}_{L M 4}=\sqrt{\frac{2}{N(N-1)}} \sum_{i=1}^{N-1} \sum_{j=i+1}^{N} \frac{(T-k) \hat{\rho}_{i j}^{2}-\mu_{T i j}}{v_{T i j}} \sim \mathrm{N}(0,1)
$$

test istatistiklerinin hipotezleri şu şekilde ifade edilmiştir:

$H_{0}$ : yatay kesit bağımlılığı yoktur

$\mathrm{H}_{1}$ : yatay kesit bağımlılığı vardır

Test sonucunda elde edilen olaslık değerleri anlamlılık düzeylerinden büyükse (\%1, \%5 ve \%10) $H_{1}$ hipotezi reddedilip, $H_{0}$ hipotezi kabul edilmektedir. Tam tersi durumda, olaslık değerleri anlamIlık düzeylerinden küçükse $H_{1}$ hipotezi kabul edilip, $H_{0}$ hipotezi reddedilmektedir. Yatay kesit bağımlıı̆ıııın tespiti için yapılan testler Tablo $1^{\prime}$ de sunulmuştur. Buna göre, $H_{0}$ hipotezi güçlü biçimde reddedilmektedir. Başka bir ifadeyle, serilerde ve modelde yatay kesit bağımlılığı olduğuna karar verilir. Bu sonuç, söz konusu ülkelerde meydana gelen bir şokun, diğer ülkeleri de etkilediğini gösterir. Dolayısıyla, analizdeki ülkelerden biri, politika belirlerken, diğer ülkelerin uyguladıkları politikaları ve bu ülkeleri etkileyen şokları da göz önünde bulundurması gerekir. 
Eskişehir Osmangazi Üniversitesi Sosyal Bilimler Dergisi

Tablo 1. Yatay Kesit Bağımlııı̆ı Test Sonuçları

\begin{tabular}{|c|c|c|c|c|}
\hline & $\mathrm{CD}_{L M 1}$ & $\mathrm{CD}_{L M 2}$ & $\mathrm{CD}_{L M 3}$ & $\mathrm{CD}_{L M 4}$ \\
\hline \multirow{2}{*}{ INC1 } & 258.532 & 4.733 & -1.102 & -1.876 \\
\hline & $(0.000)$ & $(0.000)$ & $(0.135)$ & (0.970) \\
\hline \multirow{2}{*}{ OVE1 } & 267.491 & 5.218 & -1.898 & -0.515 \\
\hline & $(0.000)$ & $(0.000)$ & $(0.029)$ & (0.697) \\
\hline \multirow{2}{*}{ INC2 } & 2027.360 & 41.552 & 3.982 & 13.348 \\
\hline & $(0.000)$ & $(0.000)$ & $(0.000)$ & $(0.000)$ \\
\hline \multirow{2}{*}{ OVE2 } & 996.107 & 11.628 & -1.691 & 11.227 \\
\hline & $(0.000)$ & $(0.000)$ & $(0.045)$ & $(0.000)$ \\
\hline \multirow{2}{*}{ INC3 } & 216.197 & 9.280 & -2.297 & 7.814 \\
\hline & $(0.000)$ & $(0.000)$ & (0.011) & $(0.000)$ \\
\hline \multirow{2}{*}{ OVE3 } & 167.552 & 5.674 & -1.259 & -0.099 \\
\hline & $(0.000)$ & $(0.000)$ & (0.104) & (0.539) \\
\hline \multirow{2}{*}{ INC4 } & 639.419 & 10.886 & 0.073 & 8.173 \\
\hline & $(0.000)$ & $(0.000)$ & $(0.471)$ & $(0.000)$ \\
\hline \multirow{2}{*}{ OVE4 } & 518.687 & 6.239 & -2.224 & 5.038 \\
\hline & $(0.000)$ & $(0.000)$ & $(0.013)$ & $(0.000)$ \\
\hline \multirow{2}{*}{ INC5 } & 696.274 & 13.032 & 0.427 & 8.059 \\
\hline & $(0.000)$ & $(0.000)$ & $(0.335)$ & $(0.000)$ \\
\hline \multirow{2}{*}{ OVE5 } & 584.590 & 8.816 & -1.999 & 2.383 \\
\hline & $(0.000)$ & $(0.000)$ & $(0.023)$ & (0.009) \\
\hline \multirow{2}{*}{ MODEL 1} & 1214.319 & 56.416 & 32.734 & 116.509 \\
\hline & $(0.000)$ & $(0.000)$ & $(0.000)$ & $(0.000)$ \\
\hline \multirow[b]{2}{*}{ MODEL 2} & 3574.403 & 86.369 & 53.155 & 235.708 \\
\hline & $(0.000)$ & $(0.000)$ & $(0.000)$ & $(0.000)$ \\
\hline
\end{tabular}




\begin{tabular}{lcccc}
\hline MODEL 3 & 638.074 & 40.552 & 23.235 & 77.076 \\
& $(0.000)$ & $(0.000)$ & $(0.000)$ & $(0.000)$ \\
MODEL 4 & 2096.158 & 65.867 & 39.286 & 149.411 \\
& $(0.000)$ & $(0.000)$ & $(0.000)$ & $(0.000)$ \\
MODEL 5 & 2546.768 & 82.874 & 46.270 & 155.122 \\
& $(0.000)$ & $(0.000)$ & $(0.000)$ & $(0.000)$ \\
\hline
\end{tabular}

Not: Parantez ( ) içindeki değerler olasılık değerlerini göstermektedir.

\subsection{Panel Birim Kök Testi}

Panel birim kök sınamasında, paneli oluşturan yatay kesitlerin birbirinden bağımsız olup olmadıkları konusu karşılaşılan en önemli sorundur. Panel birim kök testleri birinci nesil ve ikinci nesil testler olmak üzere ikiye ayrıır. İlki, paneli oluşturan yatay kesit birimlerinin bağımsız olduğu ve paneli oluşturan birimlerden birine gelen şoktan tüm yatay kesitlerin aynı düzeyde etkilendiklerini varsayarken, yani yatay kesit bağımlılığını dikkate almaz iken, sonraki, yatay kesit bağımlılığını göz önünde bulundurarak birim kök analizi yapar.

Bu çalışmada, etkin tahmin sonuçlarının elde edilebilmesi için öncelikle bütün serileri içeren ve yatay kesit bağımlıı̆ını dikkate alan ikinci nesil panel birim kök testleri uygulanmıştır. Daha sonra ise, yatay kesit bağımlılığı testi sonuçlarına göre yatay kesit bağımlıı̆ının bazı testler tarafından reddedildiği seriler için birinci nesil panel birim kök testlerine yer verilmiştir. Buna göre, önce Hadri ve Kurozumi (2012) tarafından geliştirilen ikinci nesil panel birim kök testi uygulanmıştır. Teste başlarken aşağıdaki model tahmin edilmektedir:

$$
\begin{aligned}
& y_{i t}=z_{i t}^{\prime} \delta_{i}+f_{t} \gamma_{i}+\varepsilon_{i t} \\
& \varepsilon_{i t}=\phi_{i 1} \varepsilon_{i t-1}+\cdots+\phi_{i p} \varepsilon_{i t-p}+v_{i t}
\end{aligned}
$$

Denklem (10)'da yer alan $z_{t}$ deterministik iken, $f_{t}$ tek boyutlu gözlemlenemeyen ortak faktördür. Bu aşamadan sonra test istatistikleri hesaplanmaktadır:

$$
\begin{aligned}
& \mathrm{Z}_{\mathrm{A}}^{\mathrm{SPC}}=\frac{1}{\widehat{\sigma}_{\mathrm{iSPC}}^{2} \mathrm{~T}^{2}}\left(\mathrm{~S}_{\mathrm{it}}^{\mathrm{W}}\right)^{2} \\
& \mathrm{Z}_{\mathrm{A}}^{\mathrm{LA}}=\frac{1}{\widehat{\sigma}_{\mathrm{iLA}}^{2} \mathrm{~T}^{2}} \sum_{\mathrm{t}=1}^{\mathrm{T}}\left(\mathrm{S}_{\mathrm{it}}^{\mathrm{W}}\right)^{2}
\end{aligned}
$$

Söz konusu testin hipotezleri şu şekilde tanımlanmıştır:

$\mathrm{H}_{0}: \phi_{\mathrm{i}}(1) \neq 0$ seride birim kök yoktur

$\mathrm{H}_{1}: \phi_{\mathrm{i}}(1)=0$ seride birim kök vardır 
Tablo 2. Hadri Kurozumi Panel Birim Kök Testi Sonuçları

\section{Düzey Değerleri}

\begin{tabular}{lllll} 
& \multicolumn{2}{c}{ Sabit } & \multicolumn{2}{c}{ Sabit ve Trend } \\
& $Z_{A}^{S P C}$ & $Z_{A}^{L A}$ & $Z_{A}^{S P C}$ & $Z_{A}^{L A}$ \\
\hline INC1 & $-3.289(0.999)^{*}$ & $-1.529(0.937)^{*}$ & $-1.049(0.853)^{*}$ & $1.935(0.026)^{*}$ \\
OVE1 & $4.665(0.000)$ & $8.2885(0.000)$ & $-2.062(0.980)^{*}$ & $-1.245(0.893)^{*}$ \\
INC2 & $-3.188(0.999)^{*}$ & $3.048(0.001)$ & $14.235(0.000)$ & $47.353(0.000)$ \\
OVE2 & $-3.515(0.999)^{*}$ & $-3.893(1.000)^{*}$ & $-0.848(0.802)^{*}$ & $-0.922(0.821)^{*}$ \\
INC3 & $-2.248(0.987)^{*}$ & $-1.167(0.878)^{*}$ & $-2.102(0.982)^{*}$ & $1.35(0.090)^{*}$ \\
OVE3 & $1.368(0.085)^{*}$ & $3.104(0.001)$ & $0.759(0.223)^{*}$ & $1.726(0.042)^{*}$ \\
INC4 & $-1.464(0.928)^{*}$ & $2.515(0.005)$ & $-1.492(0.932)^{*}$ & $2.337(0.009)$ \\
OVE4 & $-2.015(0.978)^{*}$ & $-0.785(0.783)^{*}$ & $0.207(0.417)^{*}$ & $-2.356(0.990)^{*}$ \\
INC5 & $-3.798(0.999)^{*}$ & $-2.914(0.998)^{*}$ & $-3.388(0.999)^{*}$ & $-2.583(0.995)^{*}$ \\
OVE5 & $-1.020(0.846)^{*}$ & $0.664(0.253)^{*}$ & $0.219(0.385)^{*}$ & $4.329(0.000)$ \\
\hline
\end{tabular}

Not: *, ** ve ***; \% 1, \% 5 ve \% 10 anlamlılık düzeyine göre durağanlığı göstermektedir. Parantez içindekiler olasıllk değerlerini göstermektedir

Tablo 2' deki bulgulara göre, serilerin büyük çoğunluğu için birim kök sorunu olmadığına, serilerin düzey değerinde durağan olduklarına karar verilmiştir. Sonraki aşamada, Levin, Lin, Chu (2002) tarafından geliştirilen birinci nesil panel birim kök testi uygulanmıştır. Daha öncede belirtildiği gibi, bu test, sadece yatay kesit bağımlıı̆ı̆ı testi sonuçlarına göre, yatay kesit bağımlılığı olduğu şüphesine düşülen seriler (INC1, OVE1, OVE3, INC4 ve INC5) için uygulanmıştır. Söz konusu testte (14-16) denklemlerinde verilen modeller tahmin edilmektedir:

Model 1: $\Delta \mathrm{y}_{\mathrm{it}}=\delta \mathrm{y}_{\mathrm{it}-1}+\varphi_{\mathrm{it}}$

Model 2: $\Delta \mathrm{y}_{\mathrm{it}}=\alpha_{0 \mathrm{i}}+\delta \mathrm{y}_{\mathrm{it}-1}+\varphi_{\mathrm{it}}$

Model 3: $\Delta \mathrm{y}_{\mathrm{it}}=\alpha_{0 \mathrm{i}}+\alpha_{1 \mathrm{i}} \mathrm{t}+\delta \mathrm{y}_{\mathrm{it}-1}+\varphi_{\mathrm{it}}$

Denklem (14-16)'da ki $y_{i t}$ serisine göre, hipotezler şöyle tanımlanmıştır:

$\mathrm{H}_{0}: \delta<0$ seride birim kök vardır

$\mathrm{H}_{1}: \delta=0$ seride birim kök yoktur 
Tablo 3. Levin, Lin, Chu Panel Birim Kök Testi Sonuçları

\begin{tabular}{cc}
\hline Değişkenler & Düzey Değerleri \\
\hline INC1 & $-5.700(0.000)$ \\
OVE1 & $-3.546(0.000)$ \\
OVE3 & $-2.333(0.009)$ \\
INC4 & $-3.143(0.000)$ \\
INC5 & $-4.100(0.000)$ \\
\hline
\end{tabular}

Not: * ** ve ***; \% 1, \% 5 ve \% 10 anlamllık düzeyine göre durağanlı̆ı, ( ) içindeki değerler ise olasılık değerlerini göstermektedir. Optimal gecikme uzunluğu Schwarz bilgi ölçütüne (SIC) göre belirlenmiştir. Tüm değişkenler için sabit terim ve trendli model (model 3) kullanılmıştır.

Tablo 3'de ki bulgular, Hadri Kurozumi panel birim kök testi sonuçları ile tutarlıdır, yani seriler düzey değerlerinde durağandır. Dolayısıyla analize serilerin düzey değerleri kullanılarak devam edilmiştir.

\subsection{Model Tahmini}

Serilerin düzey değerlerinde durağan oldukları belirlendikten sonra 12, 3, 4 ve 5 numaralı modellerin tahmin aşamasına geçilmiştir. Panel veri modellerinin tahmininde havuzlanmış en küçük kareler, sabit etkiler modeli veya rassal etkiler modeli kullanılmaktadır.

Havuzlanmış en küçük kareler yönteminde temel varsayım şudur: Gözlemlenemeyen yatay kesit ve zaman etkileri modelde yer almaz. Söz konusu yöntem, basit olmakla birlikte kısıtlı varsayımları nedeniyle değişkenler arasındaki gerçek ilişkinin ortaya konmasında çarpık sonuçlar üretmektedir. Bu nedenle, literatürde daha çok sabit etkiler ve rassal etkiler modelleri üzerinde durulmaktadır. Sabit ve rassal etkiler modellerinde temel varsayım, gözlenemeyen yatay kesit ve/veya zaman etkilerinin modelde yer aldığı ve bu durumun göz önünde bulundurulması gerektiği biçiminde tanımlanmıştır.

$$
Y_{i t}=\beta_{1 i}+\beta_{2} X_{2 i t}+\beta_{3} X_{3 i t}+u_{i t}
$$

Denklem (17)'e göre, sabit terim yatay kesitler arasında değişebilirken, her bir yatay kesitin sabit terimi zamana göre değişememektedir, yani sabit kalmaktadır. Dolayısıyla, bu model, sabit etkiler modeli olarak tanımlanmıştır (Greene, 2004).

Rassal etkiler modelinde ise $\beta_{1 i}$ rassal bir sabit terim olarak değerlendirilmektedir.

$$
\begin{aligned}
& \beta_{1 \mathrm{i}}=\beta_{1}+\varepsilon_{\mathrm{i}} \quad \mathrm{i}=1,2, \ldots, \mathrm{N} \\
& \mathrm{Y}_{\mathrm{it}}=\beta_{1}+\beta_{2} \mathrm{X}_{2 \mathrm{it}}+\beta_{3} \mathrm{X}_{3 \mathrm{it}}+\varepsilon_{\mathrm{i}}+\mathrm{u}_{\mathrm{it}} \\
& \mathrm{w}_{\mathrm{it}}=\varepsilon_{\mathrm{i}}+\mathrm{u}_{\mathrm{it}}
\end{aligned}
$$


Burada $\varepsilon_{i}$, sabit terimin rassal olmasına sebep olan bireysel hata terimini göstermektedir.

Literatürde, panel veri regresyon tahmininde sabit ve rassal etkiler modellerinden hangisinin seçileceğine dair kesin bir ayrım yoktur. Baltagi'ye (2005) göre, hangi modelin seçileceği veri toplama süreciyle ilgilidir. Eğer, analizde belirli bir gruptan (N sayıda OECD ülkesi, N sayıda Amerika Birleşik Devletleri eyaleti gibi) seçim yapılıyorsa sabit etkiler modeli tercih edilmelidir. Aksine geniş bir ana kütleden rassal bir seçim yapılıyorsa rassal etkiler modeli tercih edilmelidir. Greene' e (2004) göre ise, Hausman testi model seçiminde tercih edilebilir. Bu nedenle, çalışmada, hem sabit etkiler modeli sonuçlarına hem de rassal etkiler modeli sonuçlarına yer verilmiştir. Sabit ve rassal etkiler varsayımı altında, tüm modeller için öncül test sonuçları EK2 ve EK3’ de rapor edilmiştir.

Öncül testlerden elde edilen sonuçlar, tüm modeller için çift yönlü sabit ve rassal etkiler modelinin geçerli olduğunu, dolayısıyla model tahminlerinin çift yönlü sabit ve rassal etkiler modeli dâhilinde yapılması gerektiğini göstermektedir. Ayrıca, tüm modellerin hata teriminde değişen varyans ve otokorelasyon sorunu ile karşılaşılmıştır. Bu nedenle, tüm modeller, değişen varyans ve otokorelasyon sorununa karşı dirençli tahmin teknikleri ile tahmin edilmiştir.

Tablo 4. Modellere ait Tahmin Sonuçları (Sabit Etkiler Modeli)

\begin{tabular}{|c|c|c|c|c|c|}
\hline & Model 1 & Model 2 & Model 3 & Model 4 & Model 5 \\
\hline $\begin{array}{l}\text { Sabit } \\
\text { Terim }\end{array}$ & $\begin{array}{c}5.699[5.357]^{*} \\
(0.000)\end{array}$ & $\begin{array}{c}3.735[6.045]^{*} \\
(0.000)\end{array}$ & $\begin{array}{c}5.859[7.608]^{*} \\
(0.000)\end{array}$ & $\begin{array}{c}6.883[12.262]^{*} \\
(0.000)\end{array}$ & $\begin{array}{c}3.345[6.700]^{*} \\
(0.000)\end{array}$ \\
\hline OVE & $\begin{array}{c}0.571[2.220]^{* *} \\
(0.027)\end{array}$ & $\begin{array}{c}1.370[9.227]^{*} \\
(0.000)\end{array}$ & $\begin{array}{c}0.682[3.630]^{*} \\
(0.000)\end{array}$ & $\begin{array}{c}0.361[2.659]^{*} \\
(0.008)\end{array}$ & $\begin{array}{c}0.799[6.405]^{*} \\
(0.000)\end{array}$ \\
\hline
\end{tabular}

Not: OVE değişkeni model 1 için OVE1; model 2 için OVE2; model 3 için OVE3; model 4 için OVE4 ve model 5 için OVE5 değişkenini temsil etmektedir. [ ] ve ( ) içindeki değerler sırasıyla t istatistik ve olasılık değerlerini ifade etmektedir. * ${ }^{* *}$ ve ${ }^{* * *}$; sırasıyla $\% 1, \% 5$ ve $\% 10$ seviyelerindeki istatistiksel anlamlılık düzeyini göstermektedir.

Model 1' e ait regresyon sonuçlarına göre, kurumsal kaliteyi temsilen kullandığımız ekonomik özgürlük endeksi ile geliri temsilen kullandığımı kişi başına GSYH arasında pozitif ve istatistiki olarak (\% 5 anlamlılık düzeyinde) anlamlı bir ilişki bulunmaktadır. Bu sonuç, Doğu ve Güney Asya ülkelerinde kurumsal kalite düzeyinde meydana gelen \% 1' lik bir artışın geliri pozitif yönde ve ortalama olarak \% 0.57 yükselttiğini göstermektedir.

Türkiye' nin de içinde bulunduğu Model 2' ye ait sonuçlara bakıldığında, ekonomik özgürlük endeksinin gelir üzerinde etkisinin pozitif ve \% 1 anlamlılık düzeyinde anlamlı olduğu görülmektedir. Buna göre, Avrupa ülkelerinde ekonomik özgürlük endeksindeki \% 1' lik bir artış geliri ortalama olarak \% 1.37 artırmaktadır. Yani kurumsal kaliteyi temsil eden ekonomik özgürlük endeksi düzeyi yükseldiğinde, gelir de yükselmektedir. 
Model 3' e ait analiz sonuçları, Ortadoğu ve Kuzey Afrika ülkelerinde, ekonomik özgürlük endeksinin pozitif ve istatistiki olarak anlamlı olduğunu ortaya koymaktadır. Burada ise, ekonomik özgürlük düzeyindeki \% 1' lik bir artış, gelir ortalama olarak \% 0.68 artırmaktadır.

Öte yandan, model 4 ve model 5' e ait regresyon sonuçları da, diğer modellerde olduğu gibi, kurumsal kalitenin gelir üzerindeki etkisinin pozitif ve istatistiki olarak anlamlı olduğunu ortaya koymaktadır. Bu sonuç, kurumsal kalitedeki \% 1' lik bir iyileşmenin ekonomik kalkınmayı ortalama olarak model 4 için \% 0.36, model 5 için \% 0.79 yükselteceğini göstermektedir. Tüm modellerden elde edilen bulgular, Scully (1988), Spindler (1991), North ve Wallis (1994), Alesina ve Rodrik (1994), Hall ve Jones (1999), Vijayaraghavan ve Ward (2001) ve Acemoğlu, Johnson, Robinson'un (2004) bulgularıyla uyumludur.

Tablo 5. Modellere ait Tahmin Sonuçları (Rassal Etkiler Modeli)

\begin{tabular}{cccccc}
\hline \hline & Model 1 & Model 2 & Model 3 & Model 4 & Model 5 \\
\hline \multirow{3}{*}{ Sabit Terim } & 3.276 & 2.785 & 5.592 & 6.696 & 3.318 \\
& {$[2.846]^{*}$} & {$[4.087]^{*}$} & {$[6.646]^{*}$} & {$[11.379]^{*}$} & {$[6.236]^{*}$} \\
& $(0.004)$ & $(0.000)$ & $(0.000)$ & $(0.000)$ & $(0.000)$ \\
& 1.157 & 1.598 & 0.747 & 0.406 & 0.806 \\
OVE & {$[4.213]^{*}$} & {$[10.136]^{*}$} & {$[3.838]^{*}$} & {$[2.972]^{*}$} & {$[6.529]^{*}$} \\
& $(0.000)$ & $(0.000)$ & $(0.000)$ & $(0.003)$ & $(0.000)$ \\
\hline
\end{tabular}

Not: OVE değişkeni model 1 için OVE1; model 2 için OVE2; model 3 için OVE3; model 4 için OVE4 ve model 5 için OVE5 değişkenini temsil etmektedir. [ ] ve ( ) içindeki değerler sırasıyla t istatistik ve olasılık değerlerini ifade etmektedir. * ** ve ***; sırasıyla $\% 1, \% 5$ ve $\% 10$ seviyelerindeki istatistiksel anlamlılık düzeyini göstermektedir.

Tablo 5 incelendiğinde, rassal etkiler varsayımı altında elde edilen katsayıların, sabit etkiler varsayımı altında elde katsayılar ile büyük ölçüde benzerlik gösterdiği, tümünün istatistiksel olarak anlamlı ve beklentiler ile uyumlu olduğu görülmektedir. Fakat EK3' te rapor edilen Hausman testi sonuçları, 1, 2, 3 ve 4 numaralı modellerde \% 10 anlamlııı düzeyinde içsellik problemi ile karşılaşıldığını, dolayısıyla 1, 2, 3 ve 4 numaralı modellerin sabit etkiler modeli varsayımı altında (Tablo 4' te rapor edilen) tahmin edilmesinin daha güvenilir olacağını göstermektedir. Bu kapsamda, Baltagi (2005) ve Greene (2004) tarafından, model seçimi için öne sürülen yöntemlerde benzer sonuçlara ulaşıldığı söylenebilir. Daha açık bir ifadeyle, Baltagi (2005) ve Greene'nin (2004) öne sürdüğü her iki yöntemde kullanıldığında model 5 hariç, tüm modeller için sabit etkiler modelinin daha uygun olduğu görülmektedir. 
Sabit ve rassal etkiler modeli varsayımı altında tahmin edilen model $5^{\prime}$ in katsayıları incelendiğinde ise, her iki katsayının da istatistiki olarak anlamlı ve pozitif olduğu, kurumsal kalitedeki \% 1' lik bir artışın geliri sabit etkiler modeli varsayımı altında \% 0.79, rassal etkiler modeli varsayımı altında $\% 0.80$ artıracağı görülmektedir. Her iki model arasında sadece 0.01 puanlık çok küçük bir fark vardır. Sabit etkiler modeli varsayımı altında tahmin edilen katsayının, rassal etkiler modeli varsayımı altında tahmin edilen katsayı ile benzer ve istatistiki olarak anlamlı olması katsayıların anlamlılığını güçlendirmektedir.

Burada, dikkat edilmesi gereken en önemli noktalardan biri sabit etkiler modeli varsayımı altında tahmin edilen modellerde, kurumsal kalitenin ekonomik kalkınma üzerindeki etkisinin en yüksek, Avrupa ülkeleri için tahmin edilen model ile (model 2) Sahra Altı Afrika ülkeleri için tahmin edilen modelde (model 5); en düşük, Doğu ve Güney Asya ülkeleri için tahmin edilen model ile (model 1) Kuzey ve Latin Amerika ülkeleri için tahmin edilen modelde (model 4) ortaya çıkmasıdır. Bu sonuç, öncelikli olarak, katsayının yüksek olduğu modellerde birbirine çok yakın ekonomik ve sosyal yapıya sahip olan ülkelerin (göreli olarak homojenliği yüksek) (Fransa-Almanya, Finlandiya-Norveç,); katsayının düşük olduğu modellerde ise birbirine benzer olmayan kalkınmışlık düzeyine sahip olan ülkelerin (göreli olarak Heterojenliği yüksek) (Avustralya-Bangladeş, Amerika-Dominik Cumhuriyeti) bir arada modellenmesinden kaynaklanıyor olabilir. Bu sonucun ikinci muhtemel nedeni ise, birinci nedenin bir uzantısı olarak, katsayının yüksek olduğu modellerde kullanılan ülkelerin model 1 için genel olarak gelişmiş ülkelerden, model 4 için ise, ekonomik ve sosyal olarak geri kalmış ülkelerden oluşması olabilir.

\section{Sonuç}

Bu çalışmada, kurumsal kalite ile gelir arasındaki ilişki, belirlenen ülke gurupları için, panel veri yöntemi ile analiz edilmiştir. Bu amaçla, ilk olarak 1996-2012 yılları arasını kapsayan dönemde, ele alınan 122 ülke Dünya Bankası' nın, ülkelerin bulunduğu bölgeyi temel alarak yapmış olduğu sınıflandırma göz önünde bulundurularak; Doğu ve Güney Asya, Avrupa, Orta Doğu ve Kuzey Afrika, Kuzey ve Latin Amerika, Sahra Altı Afrika olmak üzere beş kategoriye ayrılmış ve beş farklı model oluşturulmuştur. Daha sonra, panel veri analizi kapsamında, paneli oluşturan yatay kesitler arasındaki bağımlıık ve serilerin düzey değerinde durağan olup olmadıkları test edilmiştir. Tüm modeller için yatay kesit bağımlılı̆ına ve tüm serilerin düzey değerinde durağan olduklarına karar verildikten sonra, etkinin yönünü ve derecesini belirlemek amacıyla her bir kategori için oluşturulan beş farklı modelin tahmini yapılmıştır. Model tahmini hem sabit etkiler modeli hem de rassal etkiler modeli varsayımı altında gerçekleştirilmiştir.

Sabit etkiler modeli varsayımı altında elde edilen sonuçlar, kurumsal kalitedeki \% 1' lik artışın, geliri ortalama olarak model 1 (Doğu ve Güney Asya) için \% 0.57, model 2 (Avrupa) için \% 1.37, model 3 (Orta Doğu ve Kuzey Afrika) için \% 0.68, model 4 (Kuzey ve Latin Amerika) için \% 0.36 ve model 5 (Sahra Altı Afrika) için \% 0.79 artıracağını göstermiştir. Rassal etkiler modeli varsayımı altında elde edilen sonuçlar ise, kurumsal kalitedeki \% 1' lik artışın, geliri ortalama olarak model 1 için \% 1.15, model 2 için \% 1.59, model 3 için \% 0.74, model 4 için \% 0.40 ve model 5 için $\% 0.80$ yükselteceğini göstermiştir. Elde edilen tüm katsayılar beklentilerle ve daha önce yapılan çalışmalar ile uyumlu olarak pozitif ve istatistiksel olarak anlamlı bulunmuştur. Her ne kadar Hausman testi sonuçları model 
5 hariç diğer tüm modellerin rassal etkiler modeli ile tahmininde içsellik problemi ile karşılaşıldığını, dolayısıyla 1, 2, 3 ve 4 numaralı modellerin sabit etkiler modeli ile tahmin edilmesinin daha güvenilir sonuçlar vereceğini gösterse de, her iki modelden elde edilen katsayıların birbirine çok yakın olması, katsayıların anlamılı̆̆ını güçlendirmektedir.

Ampirik analizlerden elde edilen üç önemli sonuç bulunmaktadır. Birincisi, bütün modeller için kurumsal kalite ile gelir arasında pozitif ve istatistiki olarak anlamlı ilişki söz konusudur. Elde edilen bu bulgu, Spindler (1991), Alesina ve Perotti (1993), North ve Wallis (1994), Alesina ve Rodrik (1994), Hall ve Jones (1999), Vijayaraghavan ve Ward (2001) ve Acemoğlu, Johnson, Robinson'un (2004) bulgularıyla örtüşmektedir. Elde edilen ikinci önemli sonuç ise, kurumsal kalitenin gelir üzerindeki etkisinin en yüksek, Avrupa ülkelerini kapsayan model 2 ile Sahra Altı Afrika ülkelerini kapsayan model 5' te; en düşük, Doğu ve Güney Asya ülkelerini kapsayan model 1 ile Kuzey ve Latin Amerika ülkelerini kapsayan model 4' te ortaya çıkmasıdır. Bu durumun en muhtemel nedeni ise, katsayının yüksek olduğu model 2 ve model 5 ' te benzer ekonomik ve sosyal yapıya sahip ülkelerin aynı model içinde yer almasıdır. Daha açık bir ifade ile, model 2' de Fransa, Almanya, Finlandiya, Norveç gibi gelişmiş ülkelerin, model 5' de Kamerun, Tanzanya, Etiyopya, Zambiya gibi azgelişmiş ülkelerin yer alması, söz konusu modellerde, kurumsal kalitenin gelir üzerindeki etkisini ölçen katsayının daha yüksek çıkmasına neden olmuştur. Buradan hareketle, üçüncü önemli bulgumuz ortaya çıkmaktadır. Kurumsal kalitenin gelire etkisi, ekonomik kalkınmaya yeni başlayacak/başlamış olan ülkelerde ve ekonomik kalkınmasını büyük çoğunlukla tamamlamışülkelerde daha yüksektir.

Elde edilen ampirik sonuçlara göre, azgelişmiş ülkeler ile gelişmiş ülkeler arasındaki yaşam standardı ve refah düzeyi arasındaki farkın kapanmasında kurumsal kalite büyük önem arz etmektedir. Bu nedenle, özellikle azgelişmiş ülkelerin, kurumsal kalitelerini iyileştirmeye yönelik gerekli hukuksal düzenlemeleri yaparak, rüşvet ve yolsuzluğu azaltmalı, mülkiyet haklarını güvence altına alan, işgücü ve iş özgürlüğüne önem veren iyi kurumları oluşturmaları gerekmektedir.

\section{Ekler}

EK1. Analizde Kullanılan Ülkeler

\begin{tabular}{ccccc}
\hline $\begin{array}{c}\text { Doğu ve Güney } \\
\text { Asya }\end{array}$ & Avrupa & $\begin{array}{c}\text { Orta Doğu ve } \\
\text { Kuzey Afrika }\end{array}$ & $\begin{array}{c}\text { Kuzey ve Latin } \\
\text { Amerika }\end{array}$ & Sahra Altı Afrika \\
\hline $\begin{array}{c}\text { Avustralya } \\
\text { Bangladeş }\end{array}$ & Arnavutluk & Cezayir & Arjantin & Benin \\
Çin & Beyazturya & Bahreyn & Bahamalar & Botsvana \\
Fiji & Belçika & Mısır & Barbados & Burkina Faso \\
Hong Kong & Bulgaristan & İran & Bolivya & Kamerun \\
Hindistan & Hırvatistan & Ürdün & Brezilya & Cape Verde \\
Endonezya & Kıbrıs & Kuveyt & Kanada & Kongo Cum. \\
\hline
\end{tabular}


Eskişehir Osmangazi Üniversitesi Sosyal Bilimler Dergisi

\begin{tabular}{|c|c|c|c|c|}
\hline Japonya & Çek Cumhuriyeti & Lübnan & Kolombiya & Etiyopya \\
\hline Güney Kore & Danimarka & Fas & Kosta Rika & Gabon \\
\hline Malezya & Estonya & Umman & Dominik Cum. & Gana \\
\hline Moğolistan & Finlandiya & Suudi Arabistan & Ekvador & Gine \\
\hline Nepal & Fransa & Tunus & El Salvador & Kenya \\
\hline Yeni Zelanda & Gürcistan & BAE & Guatemala & Lesoto \\
\hline Pakistan & Almanya & Yemen & Guyana & Madagaskar \\
\hline Filipinler & Yunanistan & & Haiti & Malavi \\
\hline Singapur & Macaristan & & Honduras & Mali \\
\hline Sri Lanka & İrlanda & & Jamaika & Moritanya \\
\hline Tayland & İtalya & & Meksika & Mozambik \\
\hline \multirow[t]{17}{*}{ Vietnam } & Letonya & & Nikaragua & Nijer \\
\hline & Litvanya & & Panama & Nijerya \\
\hline & Lüksemburg & & Paraguay & Senegal \\
\hline & Moldova & & Peru & Güney Afrika \\
\hline & Hollanda & & Surinam & Svaziland \\
\hline & Norveç & & Trinidad Tobago & Tanzanya \\
\hline & Polonya & & Amerika & Uganda \\
\hline & Portekiz & & Uruguay & Zambiya \\
\hline & Romanya & & Venezuela & Zimbabve \\
\hline & Slovakya & & & \\
\hline & Slovenya & & & \\
\hline & İspanya & & & \\
\hline & İsveç & & & \\
\hline & İsviçre & & & \\
\hline & Türkiye & & & \\
\hline & Ukrayna & & & \\
\hline & İngiltere & & & \\
\hline
\end{tabular}


Sedat ALATAŞ | Osman PEKER

\begin{tabular}{lllll}
\hline 19 & 35 & 14 & 27 & 27 \\
\hline
\end{tabular}

EK2. Modellere ait Öncül Test Sonuçları (Sabit Etkiler Modeli)

\begin{tabular}{cccccc}
\hline \hline Testler & Model 1 & Model 2 & Model 3 & Model 4 & Model 5 \\
\hline \multirow{2}{*}{$F_{\text {yatay kesit }}$} & 246.515 & 412.587 & 625.997 & 316.861 & 410.614 \\
& $(0.000)$ & $(0.000)$ & $(0.000)$ & $(0.000)$ & $(0.000)$ \\
$F_{\text {zaman }}$ & 81.536 & 117.193 & 72.806 & 81.081 & 97.381 \\
& $(0.000)$ & $(0.000)$ & $(0.000)$ & $(0.000)$ & $(0.000)$ \\
$F_{\text {yatay kesit+zaman }}$ & 163.955 & 299.412 & 317.503 & 236.000 & 291.228 \\
& $(0.000)$ & $(0.000)$ & $(0.000)$ & $(0.000)$ & $(0.000)$ \\
LM değişen varyans & 90.484 & 247.570 & 25.665 & 100.744 & 146.625 \\
& $(0.000)$ & $(0.000)$ & $(0.018)$ & $(0.000)$ & $(0.000)$ \\
LM & & & & \\
& 240.497 & 400.763 & 173.558 & 327.620 & 345.146 \\
\hline
\end{tabular}

Not: ( ) içindeki değerler ise olasılık değerlerini göstermektedir.

EK3. Modellere ait Öncül Test Sonuçları (Rassal Etkiler Modeli)

\begin{tabular}{|c|c|c|c|c|c|}
\hline Testler & Model 1 & Model 2 & Model 3 & Model 4 & Model 5 \\
\hline \multirow{2}{*}{$L M_{\text {yatay kesit }}$} & 913.597 & 3204.08 & 1225.95 & 1892.2 & 2538.6 \\
\hline & $(0.000)$ & $(0.000)$ & $(0.000)$ & $(0.000)$ & $(0.000)$ \\
\hline \multirow{2}{*}{$L M_{\text {zaman }}$} & 64.685 & 9.858 & 3.186 & 99.057 & 47.558 \\
\hline & $(0.000)$ & $(0.001)$ & $(0.074)$ & $(0.000)$ & $(0.000)$ \\
\hline \multirow{2}{*}{$L M_{\text {yatay kesit+zaman }}$} & 978.283 & 3213.94 & 1229.14 & 1991.2 & 2586.2 \\
\hline & $(0.000)$ & $(0.000)$ & $(0.000)$ & $(0.000)$ & $(0.000)$ \\
\hline \multirow{2}{*}{ HONDA $A_{\text {yatay kesit }}$} & 30.225 & 56.604 & 35.013 & 43.499 & 50.385 \\
\hline & $(0.000)$ & $(0.000)$ & $(0.000)$ & $(0.000)$ & $(0.000)$ \\
\hline \multirow{2}{*}{$H O N D A_{\text {zaman }}$} & 8.042 & 3.139 & 1.785 & 9.952 & 6.896 \\
\hline & $(0.000)$ & $(0.000)$ & $(0.037)$ & $(0.000)$ & $(0.000)$ \\
\hline$H O N D A_{\text {yatay kesit+zaman }}$ & 27.059 & 42.245 & 26.020 & 37.796 & 40.504 \\
\hline
\end{tabular}




\begin{tabular}{cccccc}
\hline \hline & $(0.000)$ & $(0.000)$ & $(0.000)$ & $(0.000)$ & $(0.000)$ \\
Hausman & 41.894 & 3.214 & 5.370 & 20.774 & 0.387 \\
& $(0.000)$ & $(0.072)$ & $(0.020)$ & $(0.000)$ & $(0.533)$ \\
& 112.651 & 435.346 & 47.342 & 154.38 & 261.54 \\
\hline$M_{\text {değişen varyans }}$ & $(0.000)$ & $(0.000)$ & $(0.000)$ & $(0.000)$ & $(0.000)$ \\
& 943.547 & 3204.49 & 1227.49 & 1903.6 & 2540.57 \\
\hline$M_{\text {otokorelasyon }}$ & $(0.000)$ & $(0.000)$ & $(0.000)$ & $(0.000)$ & $(0.000)$ \\
\hline
\end{tabular}

Not: ( ) içindeki değerler ise olasılık değerlerini göstermektedir.

\section{Kaynaklar}

Acemoglu, Daron, Johnson, Simon ve Robinson Johnson (2004). "Institutions As the Fundamental Cause of Long-Run Growth", National Bureau of Economic Research, NBER Working Paper No: 10481 , s. 1-92.

Acemoglu, Daron ve Simon Johnson (2003). "Unblinding Institutions", National Bureau of Economic Research, NBER Working Paper No: 9934, s. 1-39.

Acemoglu, Daron (2003). "Root Causes A Historical Approach to Assessing the Role of Institutions in Economic Development", Finance\&Development, s. 27-30.

Alesina, Alberto ve Roberto Perotti (1993). "Income Distribution, Political Instability, and Investment", National Bureau of Economic Research, NBER Working Paper No: 4486, s. 1-33.

Aron, Jannie (2000). "Growth and Institutions: A Review of the Evidence", The World Bank Research Observer, Vol. 15, No: 1, s. 99-135.

Baltagi, Badi (2005). Econometric Analysis of Panel Data (3. Edition), John Wiley Sons Ltd, West Sussex.

Bloch, Harry ve Sam Hak Kan Tang (2004). “Deep Determinants of Economic Growth: Institutions, Geography and Openness to Trade", Progress in Development Studies, Vol. 4, No: 3, s. 245-255.

Breusch, Trevor S. ve Adrian R. Pagan (1980). "The Lagrange Multiplier Test and Its Applications to Model Specification Tests in Econometrics", Review of Economic Studies, No: 47, s. 239-253.

Dampare, George A. ve Jennifer Piesse (2002). "Financial Development, Political Institutions and Economic Growth in the ECOWAS Sub-Region: An Empirical Analysis", The Management Centre, King's College London, University of London.

Dawson, John D. (1998). "Institutions, Investment, and Growth: New Cross-Country and Panel Data Evidence", Economic Inquiry, Vol. XXXVI, s. 603-619. 
Dearmon, Jacob ve Kevin Grier (2009). “Trust and Development”, Journal of Economic Behaviour \& Organization, No: 71, s. 210-220.

Deaton, Angus (1993). Data and Econometric Tools for Development Analysis, Woodrow Wilson School Development Studies, s. 1785-1874.

Dünya Bankası (2013). World Bank Development Indicators, http://databank.worldbank.org/data/reports.aspx?source=world-development-indicators

GÖKALP, Faysal M. ve Ercan BALDEMiR (2006). "Kurumsal Yapı ve Ekonomik Büyüme ilişkisi”, Dokuz Eylül Üniversitesi Sosyal Bilimler Enstitüsü Dergisi, Cilt 8, Sayı 1, s. 212-226.

Green, Willam. H. (2004). Econometric Analysis (5. Edition), Prentice Hall:, New Jersey.

Hadri, Kaddour ve Eiji KUROZUMi (2012). “A Simple Panel Stationarity Test in the Presence of Serial Correlation and a Common Factor", Economics Letter, No: 115, s. 31-34.

Hall, Robert E. ve Charles I. Jones (1998). “Why Do Some Countries Produce So Much More Output per Worker than Others?", National Bureau of Economic Research, NBER Working Paper No: 6564 , s. 1-49.

Knack, Stephen ve Philip Keefer (1995). "Institutions and Economic Performance: Cross-Country Tests Using Alternative Institutional Indicators", Munich Personal RePEc Archive, MPRA Paper No: 23118, s.1-30.

Levin, Andrew, Lin, Chien-Fu ve Chia-Shang J. Chu (2002). "Unit Root Tests in Panel Data: Asymptotic and Finite-Sample Properties", Journal of Econometrics, No: 108, s. 1-24.

Mauro, Paolo (1995). "Corruption and Growth", The Ouarterly Journal of Economics, Vol. 110, No: 3, s. 681-712.

Meier, Gerald M. ve Joseph E. Stıglitz (2000). Frontiers of Development Economics The Future in Perspective, Oxford University Press, New York.

Miras Vakfı Veri Bankası (http://www.heritage.org/index/explore 07.12.2014)

Mitchener, Kris J. ve Mari Ohnuki (2008). “Institutions, Competition, and Capital Market Integration in Japan”, National Bureau of Economic Research, NBER Working Paper No: 14090, s. 1-37.

Nafziger, Wayne E. (2006). Economic Development, Cambridge University Press, New York.

North, Douglas C. (1990). Institutions, Institutional Change and Economic Performance, Cambridge University Press, Cambridge.

North, Douglass C. ve Robert P. Thomas (1970). "An Economic Theory of the Growth of the Western World", The Economic History Review, Vol. 23, No: 1, s. 1-17. 
North, Douglass C. ve John J. Wallıs (1994). “Integrating Institutional Change and Technical Change in Economic History A Transaction Cost Approach", Journal of Institutional and Theoretical Economics, Vol. 150, No: 4, s. 609-624.

Özcan, Burcu ve Fatma Zeren (2013). "Sosyal Güvenlik ve Ekonomik Kalkınma: Avrupa Ülkeleri Üzerine Mekansal Ekonometri Analizi”, Eskişehir Osmangazi Üniversitesi iliBF Dergisi, Cilt 8, Sayı 1, s. 7-36.

Pesaran, Hashem M., Ulah, Aman ve Takashi Yamagata (2008). “A Bias-Adjusted LM Test of Error Cross-Section Independence", Econometrics Journal, No: 11, s. 105-127.

Pesaran, Hashem M. (2004). "General Diagnostic Tests for Cross Section Dependence in Panels", Cambridge Working Papers in Economics, No: 435, s. 1-39.

Pesaran, Hashem M. (2006). "Estimation and Inference in Large Heterogeneous Panels with a Multifactor Error Structure", Econometrica, Vol. 74, No: 4, s. 967-1012.

Rodrik, Dani, Subramanıan, Arvind ve Francesco Trebbi (2002). "Institutions Rule: The Primacy of Institutions over Geography and Integration in Economic Development", National Bureau Of Economic Research, NBER Working Paper No: 9305, s. 1-44.

Scully, Gerald W. (1988). "The Institutional Framework and Economic Development", Journal of Political Economy, Vol. 96, No: 3, s. 652-662.

Shafik, Nemat (1994). "Economic Development and Environmental Quality: An Econometric Analysis", Oxford Economic Papers, Vol. 46, s. 757-773.

Spindler, Zane A. (1991). "Liberty and Development: A Further Empirical Perspective", Kluver Academic Publishers, No: 69, s. 197-210.

Vijayaraghavan, Maya ve William A. Ward (2001). "Institutions and Economic Growth: Empirical Evidence from a Cross-National Analysis", Clemson University, Working Paper No: 001302, s. 125.

Yapraklı, Sevda (2008). "Kurumsal Yapının Ekonomik Büyümeye Etkisi: Üst Orta Gelir Düzeyindeki Ülkeler Üzerine Bir Uygulama”, Ege Akademik Bakış, Cilt 8, Sayı 1, s. 301-317.

Yoo, Dongwoo ve Richard H. Steckel (2010). "Property Rights and Financial Development: The Legacy of Japanese Colonial Institutions", National Bureau of Economic Research, NBER Working Paper No: 16551, s. 1-33. 